Review began 10/26/2021 Review ended 10/31/2021 Published 11/17/2021

() Copyright 2021

Irak et al. This is an open access article distributed under the terms of the Creative Commons Attribution License CC-BY 4.0., which permits unrestricted use, distribution, and reproduction in any medium, provided the original author and source are credited

\section{Evaluation of G-Protein-Coupled Bile Acid Receptor 1 (TGR5) Levels in Intrahepatic Cholestasis of Pregnancy}

Kader Irak ${ }^{1}$, Mehmet Bayram ${ }^{2}$, Sami Cifci ${ }^{1}$, Zuat Acar $^{3}$, Cemal Kazezoglu ${ }^{4}$, Deniz Ogutmen Koc ${ }^{5}$, Oyku Arslan 6

1. Gastroenterology, Basaksehir Cam and Sakura City Hospital, Istanbul, TUR 2. Gastroenterology, University of Health Sciences, Kanuni Sultan Suleyman Training and Research Hospital, Istanbul, TUR 3. Gynecology and Obstetrics, University of Health Sciences, Kanuni Sultan Suleyman Training and Research Hospital, Istanbul, TUR 4. Biochemistry, University of Health Sciences, Kanuni Sultan Suleyman Training and Research Hospital, Istanbul, TUR 5. Gastroenterology, University of Health Sciences, Gaziosmanpasa Training and Research Hospital, Istanbul, TUR 6. Hematology, Basaksehir Cam and Sakura City Hospital, Istanbul, TUR

Corresponding author: Mehmet Bayram, drmhbayram@gmail.com

\section{Abstract}

\section{Background and objective}

Intrahepatic cholestasis of pregnancy (ICP) is the most common pregnancy-related liver disease. G-proteincoupled bile acid receptor 1 (TGR5) agonists might be beneficial in ICP treatment. In this study, we aimed to investigate the relationship of serum TGR5 levels with ICP and associated itching.

\section{Methods}

Sixty-three pregnant women diagnosed with ICP based on a serum bile acid level of $>10 \mu \mathrm{mol} / \mathrm{L}$ (patient group) and 47 healthy pregnant women as a control group were included in the study. In the patient group, ursodeoxycholic acid (UDCA) therapy was given at a dose of $15 \mathrm{mg} / \mathrm{kg}$ from the time of diagnosis until the termination of pregnancy. Serum transaminase levels were measured at the beginning and within 15 days after the onset of treatment, and the dose was increased in patients who were unresponsive to treatment.

\section{Results}

Bile acid level was found to be between $10-39 \mu \mathrm{mol} / \mathrm{L}$ in $61.9 \%$ of the ICP patients, and it was $\geqslant 40 \mu \mathrm{mol} / \mathrm{L}$ in $38.1 \%$ of the patients. The majority of the patients responded well to the treatment with UDCA. The mean TGR5 level was significantly higher in the patient group compared to the control group $(0.98 \pm 0.95 \mathrm{ng} / \mathrm{mL}$ vs. $0.74 \pm 0.23 \mathrm{ng} / \mathrm{mL}, \mathrm{p}=0.032$ ). In the patient group, TGR5 level showed negative correlations with age and red cell distribution width and a positive correlation with lactate dehydrogenase level and lymphocyte count.

\section{Conclusions}

Based on our findings, it can be suggested that TGR5 may have a role in the pathogenesis but has no impact on the prognosis of the condition.

Categories: Internal Medicine, Obstetrics/Gynecology, Gastroenterology

Keywords: bile acid, itching, intrahepatic cholestasis of pregnancy, pregnancy-related liver disease, tgr5 agonists, hepatology

\section{Introduction}

Intrahepatic cholestasis of pregnancy (ICP) is the most commonly encountered pregnancy-related liver disease. It usually occurs in the third trimester of pregnancy and is characterized by typical itching and increased serum transaminase and bile acid levels [1]. Endocrine, genetic, and environmental factors play a role in the etiology of ICP [2]. Its incidence shows substantial variations among countries. In general, the incidence of ICP varies between $0.2 \%$ and $2 \%$, but it is reported that the incidence is as high as $22 \%$ in some populations [2].

The diagnosis of ICP is made based on typical complaints of palmar and plantar itching and elevated levels of serum bile acid [3]. The most sensitive and specific diagnostic marker is a serum bile acid level of $>10$ $\mu \mathrm{mol} / \mathrm{L}[4]$. ICP poses minimal risk for the mother; its symptoms regress with birth but may recur in subsequent pregnancies [3]. However, critical adverse effects have been reported in the fetus. It has been demonstrated that the risk of fetal complications is higher in cases with a serum bile acid level of $>40$ $\mu \mathrm{mol} / \mathrm{L}$. ICP-induced fetal complications include anoxia, meconium-stained amniotic fluid, prematurity, perinatal death, fetal distress, and stillbirth $[3,4]$. Such serious impacts on fetuses highlight the importance of early diagnosis and treatment of ICP. In their pilot study, Tolunay et al. found a significant positive 
association between first-trimester aspartate aminotransferase to platelet ratio index (APRI) score and third-trimester fasting bile acid level. The APRI score in the first trimester seems to predict the development of ICP in the last trimester of pregnancy [5].

The treatment of ICP is symptom-oriented. It focuses on relieving itching since itching is very troublesome for the patients, increases at night, and disturbs sleep. Ursodeoxycholic acid (UDCA) is beneficial in relieving itching by lowering bile acid levels, but there is scant evidence that it reduces perinatal complications [6]. Therefore, more effective therapies are required. The development of new therapies, however, requires more information about the pathogenesis of the disease.

Synthesis and regulation of bile acids are provided by nuclear and membrane receptors. Among these bile acid-activated receptors, farnesoid X receptor and G-protein-coupled bile acid receptor 1 (GPBAR1; TGR5) have been comprehensively studied [7]. The activation of farnesoid X receptor and TGR5 results in the decreased burden of hepatic bile salt, improved insulin sensitivity and glucose regulation, and increased energy consumption and anti-inflammatory effect [7]. TGR5 agonists might be used as potential drugs for some metabolic disorders, inflammation, and digestive disorders. Activated TGR 5 may play a role in the treatment of various metabolic disorders such as type 2 diabetes and obesity [8]. In the light of this information, it is thought that TGR5 agonists might be beneficial in the treatment of ICP as well.

Furthermore, it could be possible to diagnose ICP early, to detect patients who potentially would have severe disease, and foresee the risks in subsequent pregnancies by measuring TGR5 levels, and thereby minimize the potential risks for the fetus and the mother by closely monitoring the patients. Based on this hypothesis, we aimed to investigate the relationship of serum TGR5 levels with ICP and associated itching in this study.

\section{Materials And Methods}

Patients with itching and serum transaminase levels higher than normal during pregnancy and who consulted gastroenterology and were accordingly diagnosed with ICP based on a serum bile acid level of $>10$ $\mu \mathrm{mol} / \mathrm{L}$ were included in the study. Patients with pregnancy-related diseases such as gestational diabetes, preeclampsia, eclampsia, or fatty liver of pregnancy, and those with a history of cholestatic liver disease (primary biliary cholangitis, primary sclerosing cholangitis) were excluded. A control group was formed comprising women having normal pregnancies. Written informed consent was obtained from the participants. The study protocol adhered to the ethical guidelines of the 1975 Declaration of Helsinki. The study was approved by the Ethics Committee of Kanuni Sultan Suleyman Training and Research Hospital (No: KAEK/2020.07.149. Date: 23.07.2020).

The age of the participants, number of pregnancies, and gestational age were recorded for both the patient and control groups. Routine complete blood count and biochemical parameters were measured. In addition, fasting blood samples were collected in plain tubes for TGR5 measurement, and they were centrifuged at $3000 \mathrm{rpm}$ for 10 minutes to obtain serum samples. TGR5 level was measured in $\mathrm{ng} / \mathrm{mL}$. In the patient group, UDCA therapy was given at a dose of $15 \mathrm{mg} / \mathrm{kg}$ from the time of diagnosis of ICP until the termination of pregnancy. Serum transaminase levels were measured again within 15 days after the onset of treatment, and the dose was increased in patients who were unresponsive to treatment.

The PASW Statistics for Windows, Version 18.0 (IBM, Armonk, NY) was used for statistical analysis. Descriptive statistics were expressed as number and percentage for categorical variables and as mean, standard deviation, median, first quartile (Q1) (percentile 25), and third quartile (Q3) (percentile 75) for numerical variables. The suitability of variables to normal distribution was analyzed using visual (histogram and probability graphics) and analytic (Kolmogorov-Smirnov/Shapiro-Wilk tests) methods. Chi-square test statistics were used for paired and multiple group comparisons of categorical variables. Paired group comparisons of numerical variables were performed using the Student's t-test in case the condition of normal distribution was met, whereas the Mann-Whitney U test was used in case the condition of normal distribution was not met. Correlation between TGR5 level and numerical variables was analyzed by the Spearman's rho test in case the condition of normal distribution was not met. A p-value of $<0.05$ was considered statistically significant.

\section{Results}

The study comprised 63 pregnant women diagnosed with ICP as the patient group and 47 age-matched normal pregnant women as the control group. A comparison of the general characteristics between the patients and the control group is presented in Table 1. Gestational age, alanine aminotransferase, aspartate aminotransferase, total bilirubin, direct bilirubin, hemoglobin, platelet, and platelet/lymphocyte values were significantly higher and lymphocyte values were significantly lower in the ICP group when compared to the control group (Table 1). 


\section{Cureus}

\begin{tabular}{|c|c|c|c|c|c|c|c|}
\hline \multirow[t]{2}{*}{ Variables } & \multicolumn{3}{|c|}{ Patient group } & \multirow[b]{2}{*}{$\mathrm{N}$} & \multicolumn{3}{|l|}{ Control group } \\
\hline & $\mathrm{N}$ & Mean $\pm S D$ & Median (Q1-Q3) & & Mean \pm SD & Median (Q1-Q3) & P-value \\
\hline Age in years & 63 & $28.7 \pm 5.76$ & $28(24-33)$ & 47 & $29.47 \pm 5.7$ & $28(25-35)$ & 0.488 \\
\hline Number of pregnancies & 61 & $2.46 \pm 1.46$ & $2(1-3)$ & 47 & $2.68 \pm 1.27$ & $3(2-4)$ & 0.252 \\
\hline Gestational age (weeks) & 60 & $31.53 \pm 5.07$ & $33(31-34)$ & 47 & $28.79 \pm 5.74$ & $28(23-35)$ & 0.018 \\
\hline ALT, U/L & 62 & $125.53 \pm 118.79$ & $72(48-165)$ & 47 & $11 \pm 5.14$ & $9(8-13)$ & $<0.001$ \\
\hline AST, U/L & 62 & $72.87 \pm 53.25$ & $56.5(38-92)$ & 47 & $14.77 \pm 2.86$ & $14(13-17)$ & $<0.001$ \\
\hline Total bilirubin, mg/dL & 60 & $0.57 \pm 0.37$ & $0.5(0.32-0.72)$ & 47 & $0.24 \pm 0.09$ & $0.23(0.15-0.3)$ & $<0.001$ \\
\hline Direct bilirubin, mg/dL & 60 & $0.38 \pm 0.3$ & $0.28(0.2-0.51)$ & 47 & $0.12 \pm 0.03$ & $0.11(0.1-0.12)$ & $<0.001$ \\
\hline Hemoglobin, g/dL & 62 & $11.64 \pm 1.33$ & $11.65(10.9-12.7)$ & 47 & $11.15 \pm 1.15$ & $11.2(10.5-12.1)$ & 0.049 \\
\hline WBC, $\times 10^{3} / \mathrm{mm}^{3}$ & 62 & $9.44 \pm 1.91$ & $9.5(8.2-10.6)$ & 47 & $9.17 \pm 2.58$ & $9.12(7.92-10.85)$ & 0.534 \\
\hline$M P V, f L$ & 62 & $11.15 \pm 1.13$ & $11.15(10.2-11.8)$ & 47 & $11.06 \pm 1.17$ & $11(10.1-12)$ & 0.609 \\
\hline RDW, \% & 62 & $13.51 \pm 1.58$ & $13.1(12.6-13.8)$ & 47 & $13.29 \pm 0.96$ & $13.2(13-13.7)$ & 0.518 \\
\hline Neutrophil, $\times 10^{3} / \mathrm{mm}^{3}$ & 62 & $6.89 \pm 1.8$ & $7(5.3-7.7)$ & 47 & $7.46 \pm 1.65$ & $7.71(6.32-8.4)$ & 0.097 \\
\hline Lymphocyte, $\times 10^{3} / \mathrm{mm}^{3}$ & 62 & $1.8 \pm 0.46$ & $1.8(1.6-2)$ & 47 & $1.97 \pm 0.37$ & $1.9(1.6-2.3)$ & 0.049 \\
\hline Platelet, $\times 10^{3} / \mathrm{mm}^{3}$ & 62 & $244.32 \pm 75.02$ & $231.5(194-281)$ & 47 & $213.85 \pm 47.38$ & 213 (179-238) & 0.016 \\
\hline Neutrophil/lymphocyte & 62 & $4.15 \pm 1.87$ & $3.85(2.85-4.7)$ & 47 & $3.9 \pm 1.01$ & $3.83(3.16-4.56)$ & 0.998 \\
\hline Platelet/lymphocyte & 62 & $143.55 \pm 55.22$ & $124.41(107.33-176.43)$ & 47 & $112.46 \pm 31.19$ & 116.8 (91.58-131.3) & 0.009 \\
\hline
\end{tabular}

\section{TABLE 1: General characteristics of the patient and control groups}

ALT: alanine aminotransferase; AST: aspartate aminotransferase; MPV: mean platelet volume; RDW: red cell distribution width; SD: standard deviation; WBC: white blood cell

While bile acid level was between $10 \mu \mathrm{mol} / \mathrm{L}$ and $39 \mu \mathrm{mol} / \mathrm{L}$ in $61.9 \%$ of ICP patients, it was $\geqslant 40 \mu \mathrm{mol} / \mathrm{L}$ in $38.1 \%$ of the patients. The majority of the patients responded well to the treatment with UDCA. The median gestational age was 37 weeks and more than half of the patients (61.5\%) gave birth by cesarean section. Admission to the ICU was required for 13 patients. Some characteristics of the patient group are given in Table 2 . 


\section{Cureus}

\begin{tabular}{|c|c|c|c|c|}
\hline Characteristics & $\mathbf{N}$ & $\mathbf{N}(\%)$ & Mean \pm SD & Median (Q1-Q3) \\
\hline Bile acid, $\mu \mathrm{mol} / \mathrm{L}$ & 63 & & $40.62 \pm 37$ & $27(16-49)$ \\
\hline Bile acid & 63 & & & \\
\hline 10-39 $\mu \mathrm{mol} / \mathrm{L}$ & & $39(61.9)$ & & \\
\hline$\geq 40 \mu \mathrm{mol} / \mathrm{L}$ & & $24(38.1)$ & & \\
\hline ALP, U/L & 54 & & $201.54 \pm 73.9$ & $201.5(144-256)$ \\
\hline GGT, U/L & 56 & & $26.8 \pm 35.78$ & $17(11.5-29)$ \\
\hline LDH, U/L & 48 & & $230.15 \pm 49.56$ & $232.5(197.5-263)$ \\
\hline Itching & 63 & & & \\
\hline Mild-moderate & & & & $22(34.9)$ \\
\hline Manifest-severe & & & & $41(65.1)$ \\
\hline UDCA dosage (x 250 mg cap/day) & 63 & & $3.57 \pm 0.73$ & $4(3-4)$ \\
\hline Alleviated itching with UDCA therapy & 52 & & & $41(78.8)$ \\
\hline ALT level with UDCA therapy & 62 & & $65.34 \pm 67.77$ & $44.5(28-69)$ \\
\hline ALT level decreased by $50 \%$ or became normal with UDCA therapy & 42 & & & $31(73.8)$ \\
\hline AST level with UDCA therapy & 59 & & $40.03 \pm 28.67$ & $34(22-54)$ \\
\hline Gestational age (weeks) & 52 & & $36.75 \pm 1.76$ & $37(36-38)$ \\
\hline Route of delivery & 52 & & & \\
\hline Cesarean section & & & & $32(61.5)$ \\
\hline Vaginal & & & & $20(38.5)$ \\
\hline Admission to the intensive care unit & 52 & & & \\
\hline No & & & & $39(75)$ \\
\hline Yes & & & & $13(25)$ \\
\hline Infant birth weight, g & 52 & & $2718.63 \pm 787.99$ & $2862.5(2370-3200)$ \\
\hline
\end{tabular}

\section{TABLE 2: Characteristics of the patient group}

The values are given as numbers (\%) or mean \pm standard deviation and median (1st quartile-3rd quartile)

GGT: gamma-glutamyl transferase; LDH: lactate dehydrogenase; UDCA: ursodeoxycholic acid

The mean \pm SD and median (Q1-Q3) levels of TGR5 (GPBAR1) was $0.98 \pm 0.95 \mathrm{ng} / \mathrm{mL}$ and $0.79(0.70-0.97)$ $\mathrm{ng} / \mathrm{mL}$, respectively, in the patient group, and $0.74 \pm 0.23 \mathrm{ng} / \mathrm{mL}$ and $0.74(0.54-0.87) \mathrm{ng} / \mathrm{mL}$, respectively, in the control group. TGR5 level was significantly higher in the patient group compared to that in the control group $(\mathrm{p}=0.032)$ (Figure 1$)$. 


\section{Cureus}

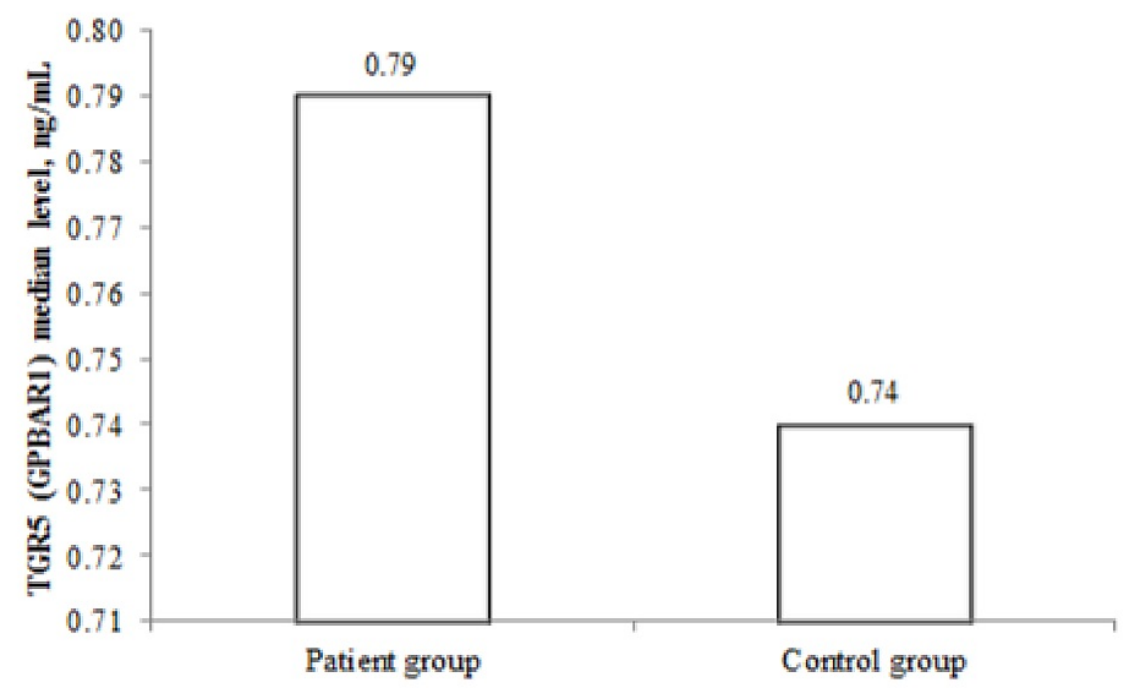

FIGURE 1: TGR5 levels in the patient and control groups

TGR5 levels were analyzed according to the characteristics of the patients. There was no significant difference in TGR5 levels between the groups established according to the characteristics (Table 3). 


\section{Cureus}

Variables

TGR5 (GPBAR1) level, ng/mL

Mean $\pm S D \quad$ Median (Q1-Q3)

Bile acid
10-39 $\mu \mathrm{mol} / \mathrm{L}$
$\geq 40 \mu \mathrm{mol} / \mathrm{L}$

Itching

\section{Mild-moderate}

Manifest-severe
$39 \quad 0.85 \pm 0.36$

$24 \quad 1.20 \pm 1.47 \quad 0.79(0.70-0.97)$

$22 \quad 0.86 \pm 0.38 \quad 0.78(0.70-0.86)$

$41 \quad 1.05 \pm 1.15 \quad 0.83(0.72-1.00)$

Alleviated itching with UDCA therapy

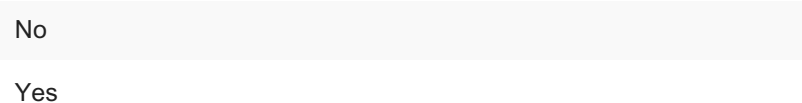

$11 \quad 0.81 \pm 0.23 \quad 0.79(0.72-0.95)$

$41 \quad 0.93 \pm 0.44 \quad 0.79(0.70-1.00)$

0.662

ALT level decreased by $50 \%$ or became normal with UDCA therapy

No

$11 \quad 0.80 \pm 0.22 \quad 0.73(0.62-1.00)$

Yes

$31 \quad 0.90 \pm 0.49 \quad 0.77(0.70-0.96)$

Route of delivery

Cesarean section
Vaginal

$32 \quad 0.93 \pm 0.33$

$0.83(0.73-1.06)$

$20 \quad 1.22 \pm 1.63$

$0.78(0.67-0.94)$

0.441

Admission to the intensive care unit
No
$39 \quad 0.95 \pm 0.46$
$0.81(0.73-1.06)$
Yes
$13 \quad 1.32 \pm 1.95 \quad 0.76(0.63-0.95)$
0.404

\section{TABLE 3: TGR5 levels according to the characteristics of the patients}

ALT: alanine aminotransferase; SD: standard deviation; Q1: first quartile; Q3: third quartile; UDCA: ursodeoxycholic acid

In the patient group, TGR5 level showed negative correlations with age and red cell distribution width, whereas there was a positive correlation with lactate dehydrogenase level and lymphocyte count (Table 4). 


\section{Cureus}

\begin{tabular}{|c|c|c|c|}
\hline \multirow[t]{2}{*}{ Variables } & \multicolumn{3}{|c|}{ TGR5 (GPBAR1) } \\
\hline & $\mathrm{N}$ & rho & P-value \\
\hline Age & 63 & -0.457 & $<0.001$ \\
\hline Gestational age & 60 & 0.123 & 0.348 \\
\hline Number of pregnancies & 61 & -0.229 & 0.076 \\
\hline Bile acid & 63 & 0.044 & 0.734 \\
\hline ALT & 62 & -0.047 & 0.715 \\
\hline AST & 62 & -0.060 & 0.642 \\
\hline Total bilirubin & 60 & -0.011 & 0.936 \\
\hline Direct bilirubin & 60 & 0.097 & 0.459 \\
\hline ALP & 54 & 0.056 & 0.686 \\
\hline GGT & 56 & -0.199 & 0.142 \\
\hline LDH & 48 & 0.381 & 0.008 \\
\hline HGB & 62 & 0.151 & 0.241 \\
\hline WBC & 62 & 0.099 & 0.444 \\
\hline MPV & 62 & -0.125 & 0.334 \\
\hline RDW & 62 & -0.263 & 0.039 \\
\hline Neutrophil & 62 & 0.011 & 0.934 \\
\hline Lymphocyte & 62 & 0.325 & 0.010 \\
\hline Platelet & 62 & -0.015 & 0.906 \\
\hline Neutrophi//lymphocyte & 62 & -0.142 & 0.272 \\
\hline Platelet/lymphocyte & 62 & -0.235 & 0.066 \\
\hline UDCA dose & 63 & 0.003 & 0.983 \\
\hline ALT with UDCA therapy & 62 & -0.076 & 0.558 \\
\hline AST with UDCA therapy & 59 & -0.024 & 0.856 \\
\hline Gestational age at birth & 52 & -0.014 & 0.923 \\
\hline Birth weight & 52 & 0.093 & 0.513 \\
\hline
\end{tabular}

\section{TABLE 4: Correlation analysis between TGR5 (GPBAR1) and other parameters in the patient}

group

ALP: alkaline phosphatase; ALT: alanine aminotransferase; AST: aspartate aminotransferase; GGT: gamma-glutamyl transferase; GPBAR1: G-proteincoupled bile acid receptor-1; HGB: hemoglobin; LDH: lactate dehydrogenase; MPV: mean platelet volume; RDW: red cell distribution width; UDCA: ursodeoxycholic acid; WBC: white blood cell

\section{Discussion}

The increasing availability of data in the last few decades about the role of bile acids as signal molecules in the regulation of metabolism has drawn the attention of researchers to this subject. There is still limited knowledge about the potential changes in the physiology of bile acids during normal pregnancy. Nevertheless, it is clearly seen in the event of ICP that pathologically elevated bile acid concentrations have a harmful impact on the mother, placenta, and developing fetus. Moreover, it has been propounded that the infants given birth by mothers with ICP become more susceptible to metabolic disorders in their future lives [9]. ICP, which is a benign condition for the mother as the symptoms relieve after birth, is associated with significant risks for the fetus [10]. Therefore, early diagnosis and treatment of ICP are especially critical for the fetus. In addition, new therapeutic options have to be devised, and a better understanding of the ICP 
pathogenesis would serve as a guide for the investigation of new therapies. TGR5, which is the subject of the present study, is among the molecules investigated for this purpose.

Plasma membrane receptor, TGR5, is found in many hepatic cells including sinusoidal endothelial cells, Kupffer cells, hepatic stellate cells, and small and large cholangiocytes. By means of TGR5, bile salts mediate choleretic, cell-protective, and proliferative effects. Impairments in these signal mechanisms may contribute to the development of biliary diseases [11,12]. Owing to its role in the pathogenesis of various diseases such as nonalcoholic steatohepatitis, hepatic diseases associated with cholestasis (primary sclerosing cholangitis and primary biliary cholangitis), polycystic liver disease, cholangiocarcinoma, portal hypertension, cirrhosis, and sepsis, TGR5 is being investigated as the potential therapeutic target in these diseases [13-16]. The activation of TGR5 has been reported to be promising in the treatment of obesity, atherosclerosis, and non-alcoholic fatty liver disease [17]. However, although data from preclinical studies about TGR5-targeted therapies are promising, it has been reported that clinical studies are inadequate [18]. TGR5 is thought to play a role in the pathogenesis of ICP, especially in relation to itching [19]. In the present study, TGR5 levels were significantly higher in pregnant women with ICP as compared to those of the normal pregnant women (median: $0.79 \mathrm{ng} / \mathrm{mL}$ vs. $0.74 \mathrm{ng} / \mathrm{mL}, \mathrm{p}=0.032$ ), indicating that TGR5 might be playing a role in the pathogenesis of cholestasis.

The main goal of the treatment of ICP is to eliminate itching. UDCA, which is recommended as the first-line treatment in some guidelines, is the most commonly used agent and has been shown to improve itching and laboratory abnormalities [20]. In their meta-analysis, Kong et al. [21] found UDCA to be effective and safe in the treatment of ICP. Nevertheless, some women are unresponsive to UDCA therapy [22]. In the present study, treatment with UDCA alleviated itching in $78.8 \%$ and decreased alanine aminotransferase levels by $50 \%$ or to normal ranges in $73.8 \%$ of the patients.

Itching is a common symptom in cholestatic liver diseases. Treatment of this troublesome symptom that impairs the quality of life is challenging $[23,24]$. The underlying mechanism of itching remains unclear. The role of various factors including bile acids, opioids, steroids, and lysophosphatidic acid has been discussed, but none of them was considered as the key mediator [23]. It has been reported that elevated bile acid concentration in circulation and in the tissues during cholestasis causes itching by activating TGR5 [24-26]. In the present study, TGR5 was higher in patients with manifest-severe itching as compared to those with mild-moderate itching even though the difference did not reach statistical significance (median: $0.83 \mathrm{ng} / \mathrm{mL}$ vs. $0.78 \mathrm{ng} / \mathrm{mL}, \mathrm{p}=0.345$ ). Nevertheless, no difference was found between the TGR5 levels of the patients showing improvement in itching with UDC therapy in comparison to those without improvement (median: $0.79 \mathrm{ng} / \mathrm{mL}$ vs. $0.79 \mathrm{ng} / \mathrm{mL}, \mathrm{p}=0.662$ ).

It has been reported that mothers with ICP may be at risk of unfavorable conditions such as liver diseases, metabolic disorders, and cancer in the long term following birth [27]. Therefore, long-term follow-up of the mothers after birth is critical for detecting subsequent impacts of ICP.

It is known that severe cholestasis is associated with neonatal morbidity [28]. In the present study, bile acid concentration was $\geqslant 40 \mathrm{\mu mol} / \mathrm{L}$ in $38.1 \%$ of ICP patients. No significant difference was found between those with a bile acid concentration of $\geqslant 40 \mu \mathrm{mol} / \mathrm{L}$ and those with a bile acid concentration between 10 and 39 $\mu \mathrm{mol} / \mathrm{L}$ in terms of TGR5 levels (median: $0.79 \mathrm{ng} / \mathrm{mL}$ vs. $0.80 \mathrm{ng} / \mathrm{mL}, \mathrm{p}=0.388$ ).

Birth at 36th gestational week in women with ICP has been reported to be the optimum birth strategy, minimizing the risk of fetal complications $[29,30]$. In the present study, the mean gestational age at birth in ICP patients was $36.75 \pm 1.76$ weeks (median: 37 weeks). Of the patients, $61.5 \%$ gave birth by cesarean section, and admission to the ICU was required for $25 \%$. The route of delivery or admission to the ICU was not found to be associated with TGR5 levels. Correlation analysis also showed no significant correlation between TGR 5 levels and concentrations of bile acids and transaminases, which are the indicators of disease severity.

The major limitations of the study are that the data were collected retrospectively and the study was conducted at a single center. In addition, the direction of the relationship between TGR5 and ICP in pregnant women could not be clearly demonstrated in the study, and a cause-effect relationship could not be shown due to the study design.

\section{Conclusions}

The present study found significantly higher TGR5 levels in ICP patients as compared to normal pregnant women. Nevertheless, no relationship was found between TGR5 levels and disease severity (bile acid and transaminase concentrations and severity of itching), response to treatment (decrease in itching and alanine aminotransferase levels), route of delivery, or admission to the ICU. This topic requires further large-scale studies with long-term follow-ups that include the postpartum period as well.

\section{Additional Information}




\section{Disclosures}

Human subjects: Consent was obtained or waived by all participants in this study. Ethics Committee of Kanuni Sultan Suleyman Training and Research Hospital issued approval KAEK/2020.07.149. This study has been approved by the Ethics Committee of Kanuni Sultan Suleyman Training and Research Hospital. Animal subjects: All authors have confirmed that this study did not involve animal subjects or tissue. Conflicts of interest: In compliance with the ICMJE uniform disclosure form, all authors declare the following: Payment/services info: All authors have declared that no financial support was received from any organization for the submitted work. Financial relationships: All authors have declared that they have no financial relationships at present or within the previous three years with any organizations that might have an interest in the submitted work. Other relationships: All authors have declared that there are no other relationships or activities that could appear to have influenced the submitted work.

\section{References}

1. Williamson C, Geenes V: Intrahepatic cholestasis of pregnancy. Obstet Gynecol. 2014, 124:120-33. 10.1097/AOG.0000000000000346

2. Marschall HU: Management of intrahepatic cholestasis of pregnancy . Expert Rev Gastroenterol Hepatol. 2015, 9:1273-9. 10.1586/17474124.2015.1083857

3. Wood AM, Livingston EG, Hughes BL, Kuller JA: Intrahepatic cholestasis of pregnancy: a review of diagnosis and management. Obstet Gynecol Surv. 2018, 73:103-9. 10.1097/OGX.0000000000000524

4. Floreani A, Gervasi MT: New insights on intrahepatic cholestasis of pregnancy . Clin Liver Dis. 2016, 20:17789. 10.1016/j.cld.2015.08.010

5. Tolunay HE, Kahraman NÇ, Varlı EN, et al.: First-trimester aspartate aminotransferase to platelet ratio index in predicting intrahepatic cholestasis in pregnancy and its relationship with bile acids: a pilot study. Eur J Obstet Gynecol Reprod Biol. 2021, 256:114-7. 10.1016/j.ejogrb.2020.11.014

6. Gabzdyl EM, Schlaeger JM: Intrahepatic cholestasis of pregnancy: a critical clinical review . J Perinat Neonatal Nurs. 2015, 29:41-50. 10.1097/JPN.0000000000000077

7. Donkers JM, Roscam Abbing RL, van de Graaf SF: Developments in bile salt based therapies: a critical overview. Biochem Pharmacol. 2019, 161:1-13. 10.1016/j.bcp.2018.12.018

8. Guo C, Chen WD, Wang YD: TGR5, not only a metabolic regulator. Front Physiol. 2016, 7:646. 10.3389/fphys.2016.00646

9. McIlvride S, Dixon PH, Williamson C: Bile acids and gestation. Mol Aspects Med. 2017, 56:90-100. 10.1016/j.mam.2017.05.003

10. Šimják P, Pařízek A, Vítek L, et al.: Fetal complications due to intrahepatic cholestasis of pregnancy . J Perinat Med. 2015, 43:133-9. 10.1515/jpm-2014-0089

11. Deutschmann K, Reich M, Klindt C, Dröge C, Spomer L, Häussinger D, Keitel V: Bile acid receptors in the biliary tree: TGR5 in physiology and disease. Biochim Biophys Acta Mol Basis Dis. 2018, 1864:1319-25. 10.1016/j.bbadis.2017.08.021

12. Di Ciaula A, Garruti G, Lunardi Baccetto R, Molina-Molina E, Bonfrate L, Wang DQ, Portincasa P: Bile Acid Physiology. Ann Hepatol. 2017, 16:S4-14. 10.5604/01.3001.0010.5493

13. Reich M, Deutschmann K, Sommerfeld A, et al.: TGR5 is essential for bile acid-dependent cholangiocyte proliferation in vivo and in vitro. Gut. 2016, 65:487-501. 10.1136/gutjnl-2015-309458

14. Reich M, Klindt C, Deutschmann K, Spomer L, Häussinger D, Keitel V: Role of the G protein-coupled bile acid receptor TGR5 in liver damage. Dig Dis. 2017, 35:235-40. 10.1159/000450917

15. Keitel V, Häussinger D: Role of TGR5 (GPBAR1) in liver disease . Semin Liver Dis. 2018, 38:333-9. 10.1055/s0038-1669940

16. Keitel V, Stindt J, Häussinger D: Bile acid-activated receptors: GPBAR1 (TGR5) and other G protein-coupled receptors. Handb Exp Pharmacol. 2019, 256:19-49. 10.1007/164_2019_230

17. Jadhav K, Xu Y, Xu Y, et al.: Reversal of metabolic disorders by pharmacological activation of bile acid receptors TGR5 and FXR. Mol Metab. 2018, 9:131-40. 10.1016/j.molmet.2018.01.005

18. van Nierop FS, Scheltema MJ, Eggink HM, Pols TW, Sonne DP, Knop FK, Soeters MR: Clinical relevance of the bile acid receptor TGR5 in metabolism. Lancet Diabetes Endocrinol. 2017, 5:224-33. 10.1016/S22138587(16)30155-3

19. Dixon PH, Williamson C: The pathophysiology of intrahepatic cholestasis of pregnancy . Clin Res Hepatol Gastroenterol. 2016, 40:141-53. 10.1016/i.clinre.2015.12.008

20. Bicocca MJ, Sperling JD, Chauhan SP: Intrahepatic cholestasis of pregnancy: review of six national and regional guidelines. Eur J Obstet Gynecol Reprod Biol. 2018, 231:180-7. 10.1016/j.ejogrb.2018.10.041

21. Kong X, Kong Y, Zhang F, Wang T, Yan J: Evaluating the effectiveness and safety of ursodeoxycholic acid in treatment of intrahepatic cholestasis of pregnancy: a meta-analysis (a prisma-compliant study). Medicine (Baltimore). 2016, 95:e4949. 10.1097/MD.0000000000004949

22. Pataia V, Dixon PH, Williamson C: Pregnancy and bile acid disorders. Am J Physiol Gastrointest Liver Physiol. 2017, 313:G1-6. 10.1152/ajpgi.00028.2017

23. De Vloo C, Nevens F: Cholestatic pruritus: an update. Acta Gastroenterol Belg. 2019, 82:75-82.

24. Hussain AB, Samuel R, Hegade VS, Jones DE, Reynolds NJ: Pruritus secondary to primary biliary cholangitis: a review of the pathophysiology and management with phototherapy. Br J Dermatol. 2019, 181:1138-45. 10.1111/bjd.17933

25. Alemi F, Kwon E, Poole DP, et al.: The TGR5 receptor mediates bile acid-induced itch and analgesia . J Clin Invest. 2013, 123:1513-30. 10.1172/JCI64551

26. Fiorucci S, Distrutti E, Ricci P, Giuliano V, Donini A, Baldelli F: Targeting FXR in cholestasis: hype or hope . Expert Opin Ther Targets. 2014, 18:1449-59. 10.1517/14728222.2014.956087

27. Ovadia C, Williamson C: Intrahepatic cholestasis of pregnancy: recent advances . Clin Dermatol. 2016, 34:327-34. 10.1016/j.clindermatol.2016.02.004 


\section{Cureus}

28. Herrera CA, Manuck TA, Stoddard GJ, et al.: Perinatal outcomes associated with intrahepatic cholestasis of pregnancy. J Matern Fetal Neonatal Med. 2018, 31:1913-20. 10.1080/14767058.2017.1332036

29. Lo JO, Shaffer BL, Allen AJ, Little SE, Cheng YW, Caughey AB: Intrahepatic cholestasis of pregnancy and timing of delivery. J Matern Fetal Neonatal Med. 2015, 28:2254-8. 10.3109/14767058.2014.984605

30. Puljic A, Kim E, Page J, Esakoff T, Shaffer B, LaCoursiere DY, Caughey AB: The risk of infant and fetal death by each additional week of expectant management in intrahepatic cholestasis of pregnancy by gestational age. Am J Obstet Gynecol. 2015, 212:667. 10.1016/j.ajog.2015.02.012 